\title{
CANAIS CURTOS DE COMERCIALIZAÇÃO E CONDIÇÕES DE VIDA DOS AGRICULTORES DE BRASÍLIA
}

\author{
http://dx.doi.org/10.21527/2237-6453.2021.57.11415
}

Recebido em: 31/8/2020

Aceito em: 28/6/2021

\author{
David Frederik da Silva Cavalcante, ${ }^{1}$ Gabriel da Silva Medina, ${ }^{2}$ \\ José Elenilson Cruz, ${ }^{3}$ Pedro Carvalho Brom ${ }^{3}$
}

\begin{abstract}
RESUMO
A comercialização com vista à melhoria das condições de vida é um desafio a ser enfrentado pelos agricultores familiares, particularmente pelos assentados da reforma agrária. Este trabalho busca averiguar se diferentes perfis produtivos e comerciais implicam alterações nos níveis dos capitais natural, financeiro, humano e social dos assentados da reforma agrária do Distrito Federal - DF. A pesquisa envolveu 156 assentados de 11 assentamentos. Os comportamentos relativos à produção e à comercialização foram utilizados como critérios para análise de cluster. Os quatro clusters identificados foram comparados a partir dos capitais por meio do teste não paramétrico de Kruskal-Wallis. Os resultados revelam que, apesar de os assentados não acessarem os canais de comercialização mais significativos em termos de volume comercializado, tais como redes varejistas e Ceasa, canais alternativos como feiras, mercados institucionais e Comunidades que Sustentam a Agricultura - CSAs - têm oportunizado aos assentados melhoraria de suas bases de recursos materiais e sociais. Esses resultados evidenciam a importância dos canais curtos de comercialização para o desenvolvimento dos assentamentos da reforma agrária do DF.
\end{abstract}

Palavras-chave: Agricultura familiar; comercialização; canais curtos.

\section{SHORT FOOD SUPPLY CHAINS AND FARMERS' LIVELIHOODS IN BRASILIA}

\begin{abstract}
Creating marketing opportunities as a means to improve livelihoods is a challenge to be faced by family farmers, particularly by land reform settlers in Brazil. This study seeks to assess whether different productive and commercial profiles imply changes in the levels of natural, financial, human and social capitals of settled farmers in the Brazilian Federal District. A survey was conducted with 156 settlers from 11 rural settlements. Behaviors related to production and commercialization were used as criteria for cluster analysis. The four identified clusters were compared based on their livelihood capitals using the Kruskal-Wallis non-parametric test. The results reveal that, although settled farmers do not access the most significant marketing channels in terms of volume sold, such as retail supply chains and the Ceasa, alternative channels such as farmers' markets, governmental procurements (institutional markets) and communities that support agriculture (CSA) have provided settlers with an opportunity to improve their livelihoods. These findings reveal the importance of short food supply chains for the development of land reform settlements in Brazil.
\end{abstract}

Keywords: Family farming, marketing, short food supply chains.

\footnotetext{
${ }^{1}$ Autor correspondente. Instituto Federal de Brasília (IFB) - Campus Gama. Setor de Múltiplas Atividades, lote 01, DF 480, Gama. Brasília/DF, Brasil. CEP 72405-980. http://lattes.cnpq.br/3911561444354916. https://orcid.org/0000-0001-8921-9794. david.cavalcante@ifb.edu.br

${ }^{2}$ Universidade Federal de Goiás (UFG). Goiânia/GO, Brasil.

${ }^{3}$ Instituto Federal de Brasília (IFB). Brasília/DF, Brasil.
} 


\section{INTRODUÇÃO}

A comercialização da produção é um desafio a ser enfrentado por agricultores familiares para a melhoria de suas condições de vida (LOURENZANI; LOURENZANI; BATALHA, 2004). O acesso aos benefícios proporcionados pela comercialização, notadamente no que corresponde a aspectos financeiros, exige dos agricultores esforço no sentido de compatibilizarem volume, qualidade da produção, logística e estratégias de comercialização em relação aos mercados. De acordo com Maluf (2004), os processos competitivos podem restringir a participação dos menos preparados, inviabilizando a sua permanência na atividade, principalmente para os que não atingirem níveis adequados de eficiência produtiva e comercial vinculados ao uso de aparatos técnicos e/ou tecnológicos. Percebe-se, assim, que o caráter recursivo da relação entre produção e comercialização exige que agricultores familiares vinculem sua atividade produtiva aos mercados, sob risco de comprometer sua sobrevivência. Não obstante essa dinâmica, análises de modelos alternativos de produção que se opõem à lógica de integração aos mercados, tal como a agroecologia, não são objeto deste trabalho, uma vez que seu enfoque é a comercialização.

No Brasil, $42 \%$ dos agricultores familiares não realizam qualquer tipo de operação comercial de sua produção agrícola (IBGE, 2020a). No Nordeste, esse percentual chega a $62 \%$ e, no Centro-Oeste, a 27\% (IBGE, 2020a). É considerável, portanto, o número de agricultores cuja produção vincula-se exclusivamente ao consumo familiar ou à manutenção da propriedade a partir do fornecimento de alimento a animais de pequeno e grande porte. Neste ponto, é importante entender que comercialização implica venda de pelo menos parte da produção.

Como destacado por Schneider e Cassol (2014especialmente no que concerneao reconhecimento da sua diversidade econômica e heterogeneidade social. O objetivo deste trabalho consiste em oferecer uma contribuição para compreensão da diversidade econômica da agricultura familiar no Brasil. Trata-se de uma síntese de um estudo mais amplo e aprofundado, realizado com base nos dados do Censo Agropecuário de 2006 sobre o perfil e as características da agricultura familiar, utilizando-se uma classificação baseada no valor da produção agropecuária desses estabelecimentos e, secundariamente, das receitas obtidas com essas atividades. Elaborou-se uma tipologia dos estabelecimentos agropecuários familiares brasileiros utilizando-se indicadores da produção (mais especificamente, o valor da produção apurado), mesmo que parcela considerável de agricultores familiares não esteja integrada aos mercados, é preciso considerar que a agricultura familiar brasileira é diversa e heterogênea. Em outros termos, no contexto da agricultura familiar a terra não se vincula exclusivamente à produção agropecuária e à geração de excedente. Além disso, o acesso e o uso de meios de produção variam entre esses agricultores, resultando em diversidade produtiva, social e econômica.

Para autores como Von Braun e Kennedy (1994) e Ellis (2000) a comercialização da produção no âmbito da agricultura familiar, além de beneficiar o núcleo familiar, tende a influenciar a comunidade na qual os agricultores estão inseridos à medida que incrementa o mercado de trabalho e melhora a circulação de renda na comunidade. Essa perspectiva alinha-se à ideia de Escobal et al. (2015), para os quais os mercados podem contribuir para o desenvolvimento local. Outro aspecto relevante da comercialização, segundo Ellis (2000), diz respeito à sua contribuição à priorização da produção agropecuária em detrimento de alternativas à geração de renda como migração e trabalho fora da propriedade. 
À medida que a comercialização proporciona maior interação com os mercados, as bases social e material vinculadas aos meios de vida de agricultores são reforçadas (PLOEG, 2016; SCOONES, 1998). Essas bases são o conjunto de artefatos físicos e de regras e normas formais e informais responsáveis pela viabilização da comercialização que, via de regra, não se enquadram nos modelos convencionais de venda de produtos agrícolas (PLOEG, 2016). Já os meios de vida são identificados por Scoones (1998) por intermédio dos capitais: natural, formado por recursos naturais e serviços ambientais; financeiro, constituído por caixa, crédito, bens econômicos como infraestrutura, equipamentos, tecnologia, etc.; humano, concernente às condições físicas e habilidades necessárias ao desenvolvimento das estratégias de sobrevivência, e social, relacionado às redes, associações, movimentos de reivindicação, etc.

Ainda que a comercialização se mostre favorável aos agricultores familiares ou mesmo que os mercados possam funcionar como geradores dos capitais (NIEDERLE, 2006), é importante ter em conta que os processos de comercialização estão organizados de várias formas (SCHNEIDER, 2016; AZEVEDO, 2012) e as exigências dos mercados relativas a custo, qualidade, intermediação, etc., assim como os respectivos retornos financeiros, variam entre as diversas possibilidades de comercialização. Em razão disso e da dificuldade de agricultores familiares priorizarem o lucro, Chiodi, Almeida e Assis (2020) questionam a compatibilidade da produção familiar com a lógica comercial estabelecida pelos mercados.

Para Mattei (2016), os assentados da reforma agrária também têm dificuldade de atender às condicionantes dos mercados, haja vista a inexperiência produtiva e comercial (SABOURIN, 2008). Esses problemas são destacados por Alves e Rocha (2010) em suas contestações acerca da política de reforma agrária. Em contrapartida porém, defensores como Barone e Ferrante (2017) afirmam que a reforma agrária é um importante instrumento de inclusão socioprodutiva e de construção de espaço para produção de alimentos saudáveis. Nessa perspectiva, Hinrichs (2000) ressalta que a busca por mercados alternativos, notadamente aqueles vinculados aos canais curtos de comercialização, tal como venda direta ao consumidor, feiras, CSA, apresenta-se como opção para a melhoria de renda e de garantia de sobrevivência de agricultores familiares. Importante esclarecer que canais curtos de comercialização são aqueles em que são estabelecidas relações entre produtores e consumidores com intermediação de, no máximo, um mediador. Por sua vez, a CSA distingue-se das demais formas de comercialização por funcionar a partir de parceria na qual consumidores compartilham os riscos com agricultores por meio do financiamento da produção e, em contrapartida, recebem periodicamente uma cesta de produtos.

O debate acerca da relevância da reforma agrária evidencia incertezas no que diz respeito às estratégias produtivas e comerciais desenvolvidas pelos assentados. Não está claro, por exemplo, se as formas de comercialização interferem nos capitais natural, financeiro, humano e social. Para autores como Ploeg (2016) e Scoones (1998), esse aspecto é importante à medida que o reforço desses capitais influenciam nos meios de vida desse grupo social.

Este trabalho tem o objetivo de analisar se diferentes perfis produtivos e comerciais de assentados implicam alteração nos níveis dos capitais natural, financeiro, humano e social. Isso, de maneira a verificar se a comercialização reflete em melhorias das condições de vida dos assentados. Especificamente, busca-se: a) caracterizar os perfis produtivos e comerciais dos assentados da reforma agrária; b) comparar os perfis produtivos e comerciais dos assentados com relação aos capitais natural, financeiro, humano e social, formadores da base social e material vinculada aos meios de vida dos assentados. 
O artigo está organizado em cinco seções. Após esta introdução, na seção seguinte os procedimentos metodológicos são apresentados. Os resultados estão na sequência e a discussão no quarto tópico. As conclusões são apresentadas no último item.

\section{METODOLOGIA}

A região de pesquisa foi delimitada ao Distrito Federal - DF, unidade federativa brasileira que ocupa área equivalente a $0,06 \%$ do território nacional e, em 2019, sua população foi estimada em 3.015.268 pessoas. São 5.246 estabelecimentos rurais, responsáveis por ocupar cerca de 21.791 pessoas (IBGE, 2020b), alcançando Valor Bruto da Produção (VBP) de R\$ 945.518.767,00 por ano (MAPA, 2020). Importante mencionar que o Distrito Federal (Figura 1) não é um Estado, tampouco possui municípios e comumente é identificado como Brasília, sede do governo federal. Ao se configurar como importante centro consumidor, além de estar próximo de cadeias agropecuárias já consolidadas e de possuir boa infraestrutura de comercialização, faz do Distrito Federal um espaço com elevado potencial para o desenvolvimento da produção agropecuária.

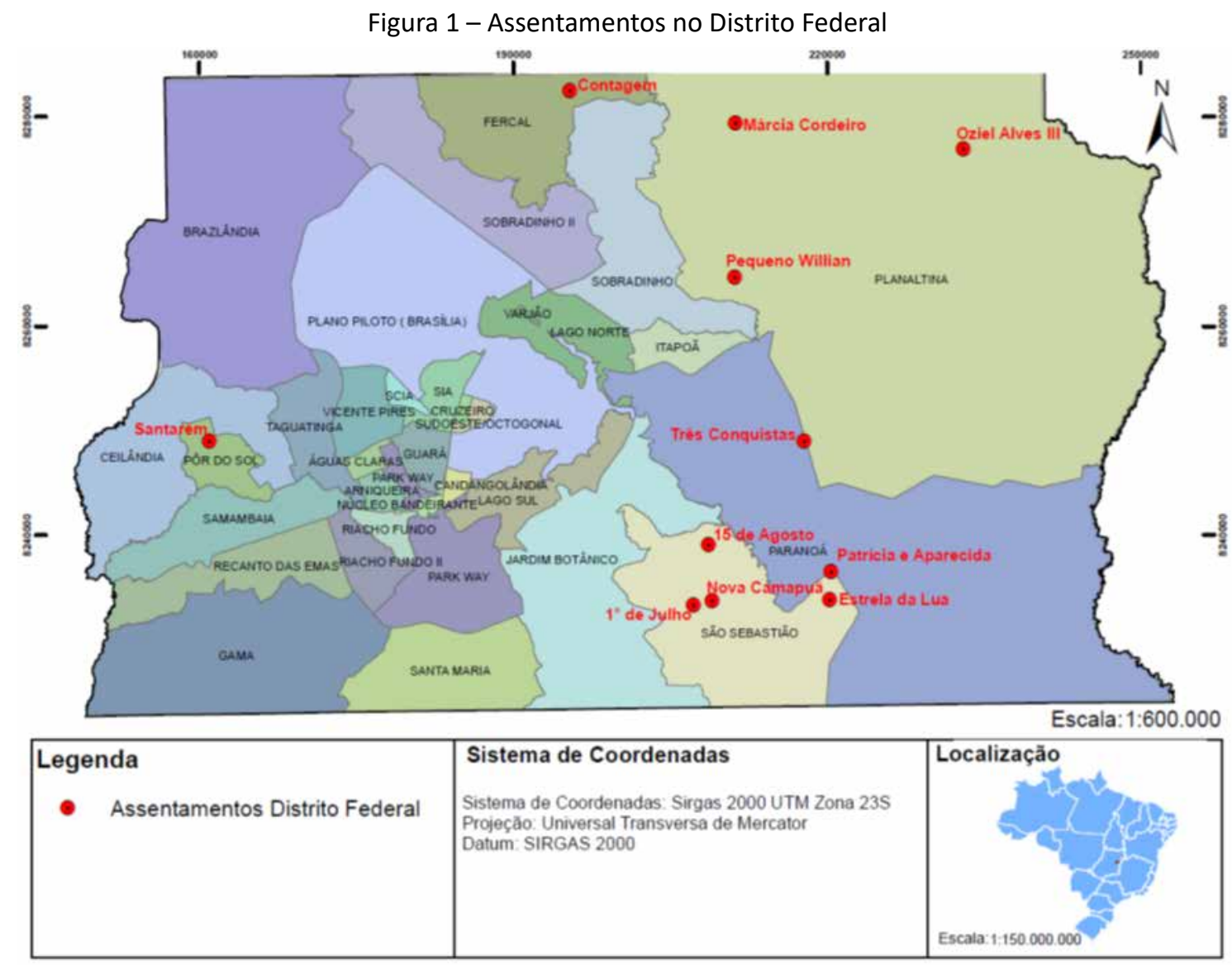

Fonte: Elaboração própria.

Apesar da identificação de 19 assentamentos no Distrito Federal (Incra, 2019), alguns assentamentos não se adequavam ao perfil da pesquisa, pois suas características estão relacionadas à realocação de moradores urbanos, não se configurando, na prática, como espaço voltado à produção agropecuária. Desse modo, a pesquisa foi realizada em 11 assentamentos (Figura 1) 
e envolveu um conjunto de 503 famílias (Tabela 1) assentadas em lotes de, em média, 9 hectares. Cabe destacar que aspectos relacionados a volume e valor da produção não se enquadram no escopo desta pesquisa.

Tabela 1 - Locais da pesquisa

\begin{tabular}{|c|l|c|}
\hline No & \multicolumn{1}{|c|}{ Assentamentos } & Famílias assentadas \\
\hline 1 & Contagem & 47 \\
\hline 2 & Márcia Cordeiro & 69 \\
\hline 3 & Oziel Alves & 161 \\
\hline 4 & Pequeno Willian & 20 \\
\hline 5 & 01 de Julho & 60 \\
\hline 6 & 15 de Agosto & 54 \\
\hline 7 & Estrela da Lua & 7 \\
\hline 8 & Patrícia e Aparecida & 24 \\
\hline 9 & Nova Camapuã & 19 \\
\hline 10 & Santarém & 22 \\
\hline 11 & Três Conquistas & 20 \\
\hline TOTAL & & 503 \\
\hline
\end{tabular}

Fonte: INCRA e EMATER/DF.

Desse universo, foram obtidas respostas de 156 assentados, o que corresponde a uma amostra aleatória com $90 \%$ de confiabilidade e margem de erro de $5 \%$. 0 número de respondentes em cada assentamento foi proporcional ao quantitativo de assentados. Já os assentados a serem entrevistados foram definidos por meio de sorteio realizado com auxílio do software Microsoft Excel, utilizando a função "aleatório". As visitas não foram agendadas previamente em virtude da preocupação com a imparcialidade de escolha dos respondentes, situação que gerou a necessidade de refazer os sorteios à medida que as pessoas sorteadas e/ou seus familiares não eram encontrados. Nesses casos, ocorria a substituição do nome mediante um novo sorteio.

Os dados foram obtidos com o uso de um formulário, preenchido nos lotes dos assentados, entre os meses de novembro de 2019 e fevereiro de 2020. Gil (2010) esclarece que o formulário exige qualificação do entrevistador, mas favorece o levantamento de dados tabuláveis e quantificáveis. As variáveis participação em organizações coletivas, assistência técnica, tipo de produção, certificação, produtos gerados na propriedade, estratégias e nível de comercialização foram definidas a partir de De Sousa Filho e Bonfim (2013), Guanziroli (2013) e Sepulcri e Trento (2010). Os capitais foram mensurados utilizando-se a escala Likert de cinco pontos nas opções de respostas discordo totalmente, discordo, não discordo nem concordo, concordo, concordo totalmente.

De início buscou-se identificar padrões responsáveis pela separação dos comportamentos relativos à produção e à comercialização. Por se tratar de variáveis categóricas, a análise de cluster foi realizada com o emprego do Método de Aprendizagem não Supervisionada - K-Modes. Esse método permitiu identificar até 10 clusters, mas optou-se por apenas 4 agrupamentos, pois a partir de 5 grupos o resultado deixa de ser informativo (Figura 2). A inclinação da curva foi o critério utilizado para a tomada de decisão. Ainda na Figura 2 pode-se constatar que após o 
40 cluster as inclinações tornam-se mais brandas, indicando que não faria diferença utilizar um maior número de clusters.

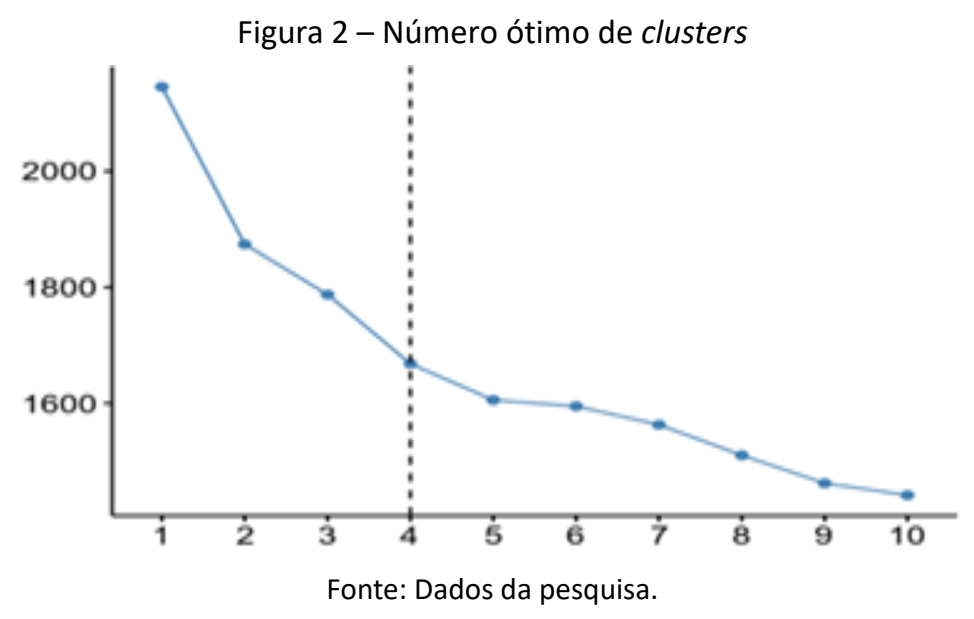

A utilização da Conditional Inference Trees - CIT - possibilitou o apontamento de padrões responsáveis pela separação dos comportamentos associados aos grupos identificados. A CIT é uma forma de classificação em que, para cada nó, é testado se a separação das respostas é significativa ou não, permitindo a hierarquização dos fatores resposáveis por apontar os padrões. A CIT, ao posicionar apenas variáveis significativas ( $p$-valor $<0.05$ ), indica, quando da realização de teste de hipótese, se as respostas são homogêneas ou não (Quadro 1). Em acréscimo, foram realizadas análises por meio de estatística descritiva de modo a permitir a sumarização dos dados.

Quadro 1 - Teste de hipótese

\begin{tabular}{|l|l|}
\hline \multicolumn{1}{|c|}{ Hipóteses } & \multicolumn{1}{c|}{ Decisão } \\
\hline HO: as respostas são homogêneas & $\begin{array}{l}\text { Deve-se rejeitar H0 e aceitar que existe evidência no contexto } \\
\text { da resposta } 1 \text { (sim) e 0 (não) }\end{array}$ \\
\hline H1: as respostas não são homogêneas &
\end{tabular}

Fonte: elaboração própria.

Por fim, como o teste de Shapiro-Wilk $(p<0,05)$ apontou que os dados não possuem distribuição normal e as variáveis não apresentam relação linear, foi empregado o teste não paramétrico de Kruskal-Wallis para comparar os capitais natural, financeiro, humano e social entre os clusters. Nessas análises, os capitais foram colocados como variáveis dependentes e os clusters como variável de agrupamento.

\section{RESULTADOS}

\section{Caracterização dos Clusters}

Além da descrição das estratégias produtivas e comerciais dos agricultores familiares assentados da reforma agrária do Distrito Federal, os clusters foram identificados a partir da característica comercial mais notória. 
Cluster 1: Feiras e mercados institucionais - formado por 37 assentados de 10 assentamentos e correspondente a $23,7 \%$ do total amostrado. Esses agricultores produzem principalmente mandioca, hortaliças, feijão e milho, além de outros produtos agrícolas, sobretudo frutas. Comercializam sua produção em feiras, especialmente mandioca, hortaliças, grãos e outros produtos agrícolas, em mercados institucionais, mandioca, hortaliças e outros produtos agrícolas e, em menor medida, para atravessadores, mandioca e hortaliças. A produção orgânica/ agroecológica chama a atenção neste grupo.

Cluster 2: Venda na propriedade - constituído por 21 assentados, 13,5\% do total amostrado, vinculados a 8 assentamentos. Mandioca, grãos, outros produtos agrícolas, porcos, galinhas caipiras e outros produtos de origem animal, principalmente ovos, compõem a matriz produtiva. A venda na propriedade envolvendo mandioca, grãos, outros produtos agrícolas, porcos, galinhas caipiras, outros produtos de origem animal, mostra-se como o principal canal de comercialização para esses produtos, ainda que feiras e mercado institucional sejam utilizados de forma restrita para a venda de outros produtos agrícolas. Neste cluster a criação de animais é tão relevante quanto a agricultura. Atravessadores vinculados a feirantes, a mercearias e a supermercados de pequeno e médio portes, além de vizinhos e moradores da região, são os principais compradores.

Cluster 3: CSA - são apenas 11 assentados, 7,1\% do total amostrado, 10 deles pertencentes a um mesmo assentamento. Todos os assentados deste grupo produzem grãos, hortaliças, mandioca e outros produtos agrícolas. A comercialização acontece quase que exclusivamente por meio de Comunidade que Sustenta a Agricultura - CSA. Apesar da ocorrência da criação de animais, a venda desses produtos não é significativa. A agricultura orgânica e agroecológica constitui-se como base da produção.

Cluster 4: Diversidade - formado por 87 assentados vinculados aos 11 assentamentos pesquisados, compreende $55,8 \%$ do total amostrado. Grãos, mandioca e hortaliças são os seus principais produtos agrícolas. A venda desses produtos é realizada principalmente na propriedade para vizinhos e para atravessadores. Já porcos e galinhas caipiras são vendidos na propriedade ou são entregues na casa do cliente.

No Quadro 2 pode ser observado o padrão de classificação dos clusters. Note-se que a relação entre produto e canal de comercialização é o que determina a separação dos grupos. As ocorrências dizem respeito aos casos em análise.

Quadro 2 - Padrão para classificação dos clusters

\begin{tabular}{lcc}
\hline \multicolumn{1}{c}{ Padrão de classificação } & Node & Ocorrências \\
\hline Venda de hortaliças na CSA (Vend_Hor_CSA) & 2 & 12 \\
\hline $\begin{array}{l}\text { Venda de mandioca na feira (Vend_Man_Fei) combinada com a venda de horta- } \\
\text { liças fora da propriedade (Vend_hor_For) }\end{array}$ & 6 & 28 \\
\hline $\begin{array}{l}\text { Venda de mandioca na feira (Vend_Man_Fei) desvinculada da venda de hortali- } \\
\text { ças fora da propriedade (Vend_hor_For) }\end{array}$ & 5 & 12 \\
\hline $\begin{array}{l}\text { Venda de outros produtos de origem animal na propriedade (Vend_OuP_Pro) } \\
\text { Ausência de interação entre as variáveis }\end{array}$ & 13 & 7 \\
\hline $\begin{array}{l}\text { Venda de grãos para o consumidor final (Vend_Gra_CoF) combinada com a ven- } \\
\text { da de suínos na propriedade (Vend_Sui_Pro) }\end{array}$ & 12 & 9 \\
\hline $\begin{array}{l}\text { Venda de grãos para o consumidor final (Vend_Gra_CoF) desvinculada da venda } \\
\text { de suínos na propriedade (Vend_Sui_Pro) }\end{array}$ & 11 & 18 \\
\hline
\end{tabular}

Fonte: Dados da pesquisa. 
Essas relações podem ser mais bem visualizadas por meio da CIT (Figura 3), na qual os nós responsáveis pela classificação dos padrões são apresentados, mostrando as relações concernentes ao teste de hipótese. A acurácia global é de $88,46 \%$ e o intervalo de confiança é de $95 \%[0,8238 ; 0,9302]$.

Figura 3 - Formação dos clusters

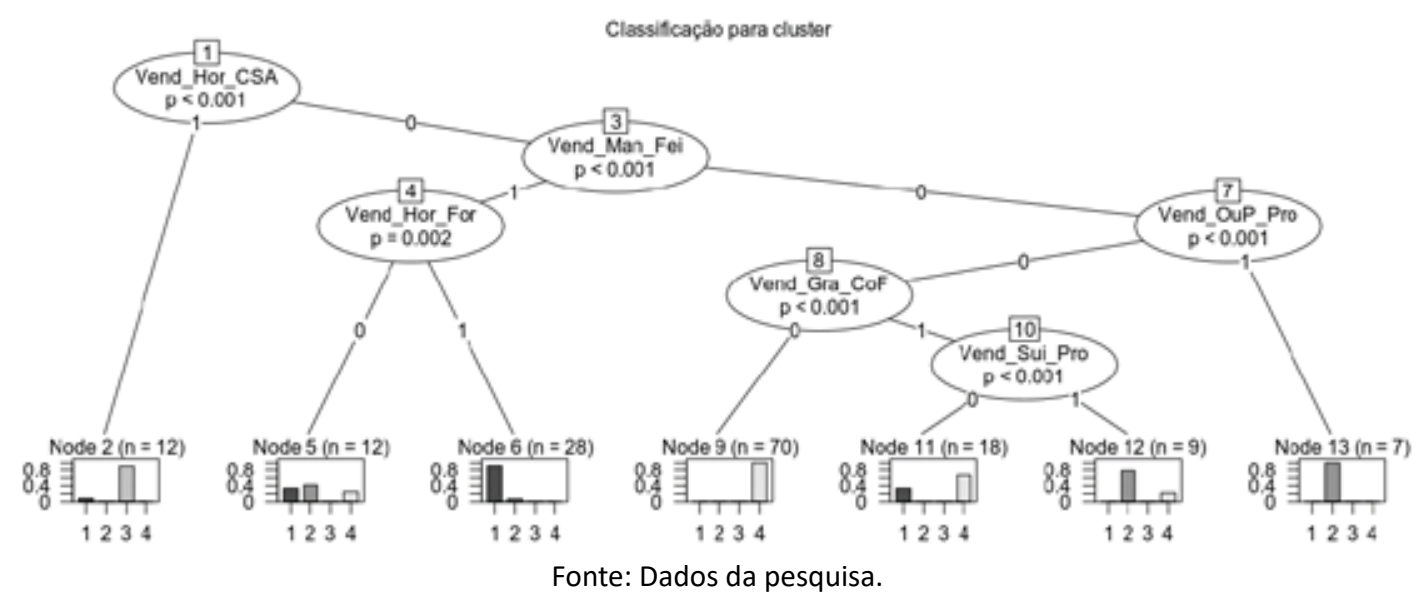

A "clusterização" revela a heterogeneidade produtiva e comercial dos assentados do Distrito Federal. 0 cluster 3, mais homogêneo em termos comerciais é também o menos numeroso, correspondendo a apenas $7,1 \%$ do conjunto de assentados. De outro lado, o mais numeroso, cluster 4 , com $55,8 \%$ do total de assentados, é também o mais diverso nos aspectos produtivo e comercial. Os resultados mostram que $80,1 \%$ dos assentados do Distrito Federal comercializam pelo menos parte de sua produção, valor que supera os $73 \%$ indicados para os agricultores familiares da Região Centro-Oeste (IBGE, 2020a).

O cluster 4, em razão do número de assentados, mostra-se mais representativo que os demais, ou seja, suas características refletem a realidade da maioria dos assentados da reforma agrária do Distrito Federal. Ocorre que neste grupo a produção não é muito diferente dos demais clusters, mas $31(35,6 \%)$ de seus assentados não comercializam sequer uma parte do que é produzido. A comercialização, apesar de envolver 56 (64,3\%) assentados do cluster 4 , encontra-se em níveis inferiores e vinculada à venda na propriedade, realizada por $43(49,4 \%)$ assentados. Desses, 37 (42,5\%) vendem seus produtos para vizinhos e familiares e 25 (28,7\%) para atravessadores. Feiras e mercados institucionais envolvem apenas $21(24,1 \%)$ assentados deste agrupamento. Destaca-se que somente $12(13,7 \%)$ assentados deste cluster apontaram o mercado como prioridade de suas atividades produtivas. É necessário ressaltar que, em razão da utilização de mais de um canal pelos assentados e não exclusivamente, esses números não totalizam 56.

No contexto geral da pesquisa, amostra de 156 assentados, $31(19,8 \%)$ assentados não comercializam a produção e $90(57,7 \%)$ utilizam feiras, mercados institucionais e CSA para vender sua produção. Isso quer dizer que $35(22,4 \%)$ daqueles que comercializam pelo menos parte da sua produção são dependentes principalmente da venda na propriedade para vizinhos e atravessadores. Tal cenário revela que há um grupo significativo de assentados que estão fora, tanto dos mercados convencionais, redes varejistas, Ceasa, indústria, etc., quanto de canais curtos baseados na diferenciação da produção tipificados aqui como mercados institucionais, CSA e 
feiras. Há muitas famílias cuja sobrevivência não está vinculada à produção e à comercialização agropecuária.

Os principais produtos comercializados pelos assentados do Distrito Federal são mandioca, hortaliças e olerícolas, especialmente frutas. É importante destacar, todavia, que em nenhum dos clusters esses produtos são significativamente comercializados junto as grandes redes varejistas ou à Central Estadual de Abastecimento - Ceasa. Por outro lado, feiras são o canal mais frequente para a comercialização de produtos pelos assentados do Distrito Federal. Elas estão presentes em todos os agrupamentos, exceto no cluster 3 . No total, 53 (33,9\%) assentados vendem seus produtos em feiras, mas é no cluster 1 em que mais se destacam, pois 29 $(78,3 \%)$ agricultores utilizam esse canal. Mercados institucionais também são meios de venda que merecem destaque, mas apenas para os clusters 1 e 2, nos quais $15(40,5 \%)$ e $6(28,5 \%)$ assentados, respectivamente, vendem por seu intermédio. No cluster 3 não há comercialização por meio de mercados institucionais e, no cluster 4 , apenas $5(5,7 \%)$ assentados acessam esses programas. Já as CSAs são o principal mecanismo de comercialização utilizado pelos assentados do grupo 3 (Quadro 3), mas não são utilizados por assentados de outros agrupamentos, exceto um caso no cluster 1. A produção orgânica/agroecológica é o tipo predominante nos clusters 1 e 3, sendo realizada por $24(64,8 \%)$ assentados do cluster 1 e $11(100 \%)$ do cluster 3 . Além disso, $13(35,1 \%)$ produtores do cluster 1 e $9(81,8 \%)$ do cluster 3 possuem certificação. Em complemento, cabe considerar que as formas de organização coletiva, associações, cooperativas e sindicatos de trabalhadores rurais, ainda que presentes, pouco contribuem para a comercialização, exceto no cluster 1 . Já no cluster 3 , mesmo os associados não relacionando comercialização e organização coletiva, isto é,venda mediada por associação ou cooperativa, as CSAs são organizadas com apoio e interveniência de uma determinada associação. 


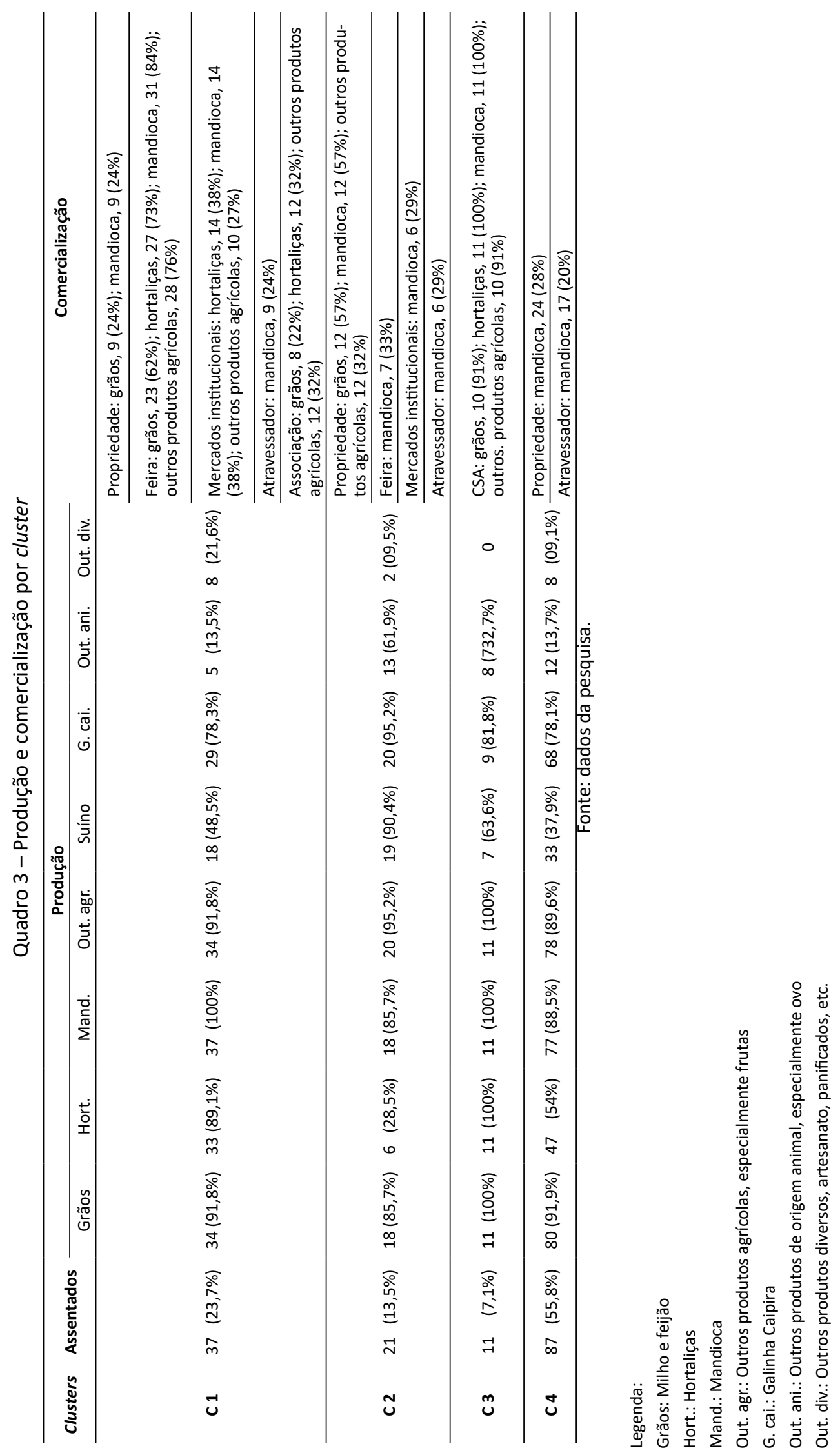




\section{Comparação entre os clusters com base nos capitais}

O teste de Kruskal-Wallis mostrou que há diferenças significativas entre os clusters considerando os capitais natural, financeiro, humano e social (Tabela 2).

Tabela 2 - Resultado do teste de Kruskal-Wallis

\begin{tabular}{|c|c|c|c|c|c|}
\hline \multirow{2}{*}{$\begin{array}{c}\text { Variável de } \\
\text { agrupamento }\end{array}$} & \multirow[b]{2}{*}{ Estatística } & \multicolumn{4}{|c|}{ Variáveis dependentes } \\
\hline & & $\begin{array}{l}\text { Capital } \\
\text { Natural }\end{array}$ & $\begin{array}{c}\text { Capital } \\
\text { Financeiro }\end{array}$ & $\begin{array}{c}\text { Capital } \\
\text { Humano }\end{array}$ & $\begin{array}{l}\text { Capital } \\
\text { Social }\end{array}$ \\
\hline \multirow{3}{*}{ Clusters } & Qui-quadrado & 23,6889 & 18,7843 & 15,9751 & 20,5561 \\
\hline & Graus de Liberdade & 3 & 3 & 3 & 3 \\
\hline & Nível de Significância & 0,000 & 0,000 & 0,000 & 0,000 \\
\hline
\end{tabular}

Fonte: Dados da pesquisa.

As comparações em par, com a correção de Bonferroni, mostraram que há diferenças entre os capitais nas seguintes situações (Tabela 3): capital natural, entre os clusters 1 e 4; 2 e 3; 3 e 4; capital financeiro, entre os clusters 3 e 4; capital humano, entre os clusters 2 e 3; 3 e 4; capital social, entre os clusters 1 e $4 ; 3$ e 4.

Tabela 3 - Diferenças entre os clusters

\begin{tabular}{lccc}
\hline Capitais & Clusters & Estatística de Teste (Z) & p-valor ajustado \\
\hline \multirow{3}{*}{ Natural } & $1-4$ & 3.254858 & 0.0034 \\
\cline { 2 - 4 } & $2-3$ & -2.905783 & 0.0110 \\
\cline { 2 - 4 } & $3-4$ & 4.149880 & 0.0001 \\
\cline { 2 - 4 } Financeiro & $1-4$ & 2.560640 & 0.0313 \\
\cline { 2 - 4 } & $2-3$ & -2.552264 & 0.0321 \\
\cline { 2 - 4 } Humano & $3-4$ & 3.897742 & 0.0003 \\
\cline { 2 - 4 } & $2-3$ & -3.353521 & 0.0024 \\
\hline \multirow{2}{*}{ Social } & $3-4$ & 3.477619 & 0.0015 \\
\cline { 2 - 4 } & $1-4$ & 3.076645 & 0.0063 \\
\hline
\end{tabular}

Fonte: Dados da pesquisa.

A base social e material vinculada aos meios de vida de agricultores familiares assentados da reforma agrária, identificada por meio dos capitais natural, financeiro, humano e social, apresenta padrões distintos entre os clusters. Note-se, no entanto, que em nenhum dos capitais há diferença significativa entre os clusters 1 e 3 , o que reforça a perspectiva de que a comercialização é importante para a consolidação dos capitais. No conjunto das análises, o cluster 3 diferencia-se significativamente dos clusters 2 e 4, exceto na comparação envolvendo o capital social, quando não há diferença em relação ao cluster 2. Já o cluster 1 não mostra diferença em relação ao cluster 2, tampouco há diferença entre os clusters 2 e 4.

Se a comercialização, conforme Azevedo (2012), está relacionada ao atendimento das exigências específicas dos mercados e, se esse processo implica melhoria dos recursos disponíveis, tal como apontado por Niederle (2006), então os assentados dos clusters 1 e, principalmente, do cluster 3, estão em melhores condições para o enfrentamento dos desafios inerentes à dinâmica produtiva, social e econômica. Em outras palavras, o conjunto de recursos disponíveis a 
esses agricultores permite que se adaptem às circunstancias de mercado e ofereçam respostas mais adequadas às exigências para comercialização.

\section{DISCUSSÃO}

A análise dos perfis produtivos e comerciais dos assentados da reforma agrária permitiu identificar quatro grupos de assentados no Distrito Federal. O primeiro grupo destaca-se pela comercialização em feiras e mercados institucionais. No segundo grupo a venda é realizada para vizinhos e atravessadores. O terceiro grupo é marcado pela venda via CSA. Por fim, o grupo mais diverso e mais numeroso chama a atenção pelo reduzido nível de comercialização. Importante notar que, a despeito da diversificação produtiva e comercial enfatizada por Schneider e Cassol (2014)especialmente no que concerneao reconhecimento da sua diversidade econômica e heterogeneidade social. $\mathrm{O}$ objetivo deste trabalho consiste em oferecer uma contribuição para compreensão da diversidade econômica da agricultura familiar no Brasil. Trata-se de uma síntese de um estudo mais amplo e aprofundado, realizado com base nos dados do Censo Agropecuário de 2006 sobre o perfil e as características da agricultura familiar, utilizando-se uma classificação baseada no valor da produção agropecuária desses estabelecimentos e, secundariamente, das receitas obtidas com essas atividades. Elaborou-se uma tipologia dos estabelecimentos agropecuários familiares brasileiros utilizando-se indicadores da produção (mais especificamente, o valor da produção apurado, os assentados do Distrito Federal apresentam nível de comercialização $(80,1 \%)$ superior ao da região Centro-Oeste $(73 \%)$ e semelhante ao da região Sul do país (81\%) (IBGE, 2020a). O indicativo aqui é de que a proximidade de um grande centro urbano favorece a comercialização da produção, mesmo que em condições informais.

Os resultados ainda apontam que a base social e material vinculada aos agricultores diferencia-se à medida que a comercialização consolida, notadamente quando associada às feiras, aos mercados institucionais e às CSAs. Por outro lado, a identificação de assentados que pouco acessam esses canais, a exemplo do cluster 4, revela um conjunto de agricultores com menores níveis de capitais. Esses resultados alinham-se à perspectiva de Niederle (2006), segundo o qual os mercados podem funcionar como geradores dos capitais natural, financeiro, humano e social. Essa constatação mostra que a comercialização é um aspecto fundamental à promoção do desenvolvimento rural. As intervenções voltadas ao desenvolvimento de agricultores familiares assentados da reforma agrária devem incorporar em suas ações medidas voltadas à identificação e acesso a mercados.

Cabe destacar que feiras, mercados institucionais e CSA, canais em que os assentados do Distrito Federal estão conseguindo melhorar sua inserção nos mercados, são mecanismos de comercialização relacionados aos circuitos curtos de comercialização e à dinâmica regional. Embora Maluf (2004) enfatize que negócios realizados a partir de produtos artesanais, orgânicos, circuitos locais, etc., sejam restritos a grupos pequenos, no Distrito Federal esses canais são acessados por 90 (58\%) assentados. Além disso, segundo Sabourin, Tadeu da Silva e De Avila (2019), o Distrito Federal conta com cerca de 30 feiras agroecológicas, indicando que a ampliação do modelo é possível, especialmente a partir das feiras.

Os mercados institucionais, por sua vez, atendem principalmente aqueles assentados já parcialmente inseridos. Tanto é assim que nem o grupo mais avançado em termos de comercialização, cluster 3 , tampouco o menos inserido, cluster 4, utilizam o mercado institucional de 
maneira significativa. Apesar de associado à superação da produção voltada exclusivamente à produção, o crescimento desse canal depende da alocação de recursos públicos.

Já as CSAs, além de não terem como base as relações estritamente econômicas, mas a colaboração entre produtores e consumidores (HINRICHS, 2000), revelando-se de difícil efetivação, beneficiam somente $12(7,6 \%)$ assentados do Distrito Federal. Destaca-se que os assentados que comercializam por meio das CSAs não utilizam outros canais, exceto um caso do cluster 1. Essa situação implica risco à medida que problemas nas CSAs podem exigir acesso a novas formas de comercialização da produção.

É possível afirmar que a venda na propriedade para vizinhos e atravessadores e os circuitos curtos vinculados à dinâmica regional, ou seja, feiras, mercados institucionais e CSA, são os canais de comercialização mais importantes para os assentados do Distrito Federal. Apesar da venda na propriedade garantir fluxo de renda, contribui menos para a melhoria da base social e material dos assentados que feiras, mercados institucionais e CSA. Além disso, os circuitos curtos têm potencial de expansão. Nesse aspecto, destaca-se a perspectiva de Sabourin et al. (2014), para os quais a renda da população do Distrito Federal e a proximidade entre cidade e campo são características locais que facilitam a conexão entre agricultores e consumidores, convergindo para a estruturação de comercialização por meio de canais curtos.

\section{CONCLUSÃO}

Foram identificados quatro clusters de agricultores assentados no DF relativos à produção e à comercialização. 0 primeiro cluster, feiras e mercados institucionais, constituído por $23,7 \%$ dos assentados, é caracterizado pela produção agrícola, com destaque para hortaliças. Feiras e mercados institucionais são os principais canais de comercialização acessados por agricultores familiares assentados no DF. No segundo cluster - venda na propriedade - formado por $13,5 \%$ dos assentados, a criação de animais é tão relevante quanto a agricultura. Atravessadores, vizinhos e moradores da região são os principais compradores. O terceiro cluster, CSA, formado por $7,1 \%$ dos assentados, tem nas CSAs o principal canal de comercialização, e na agricultura orgânica/agroecológica a base da produção. Por fim, o quarto cluster, diversidade, formado pela maioria dos assentados (55,8\%), é caracterizado pela diversidade produtiva e pelo reduzido nível de comercialização.

Os clusters, quando analisados a partir dos capitais natural, financeiro, humano e social, mostram padrões distintos. Os assentados dos grupos feiras e mercados institucionais e CSA, clusters 1 e 3 , nos quais há maior nível de comercialização, apresentam melhores níveis desses capitais. Além disso, a distinção, em todos os capitais, entre os cluster 3 , mais inserido nos mercados, e o cluster 4, menos inserido nos mercados, confirma a importância da comercialização para a melhoria da base social e material dos assentados do Distrito Federal.

Em síntese, ao analisar se diferentes perfis produtivos e comerciais de assentados implicam alteração nos níveis dos capitais natural, financeiro, humano e social, foi possível verificar que, a despeito de não participarem dos principais mercados vinculados às redes varejistas, à Ceasa e às agroindústrias, a maioria dos assentados comercializa sua produção na propriedade, $45 \%$ desses casos para vizinhos e em $29 \%$ para atravessadores. Onde, porém, verifica-se a melhoria da base social e material, a partir de maiores níveis de produção agrícola e de comer- 
cialização, é nas feiras, para 34\% dos assentados, nos mercados institucionais, para $17 \%$ dos assentados, e nas CSAs, para 7\% dos produtores. Isso porque esses canais curtos de comercialização estão associados aos clusters 1 e 3 , os quais não apresentaram diferenças significativas em relação aos capitais.

\section{REFERÊNCIAS}

ALVES, E. R. A.; ROCHA, D. P. Ganhar tempo é possível? Texto para Discussão. FGV, Ibre, 2010. Disponível em: https://bibliotecadigital.fgv.br/dspace/handle/10438/11792. Acesso em: 9 jul. 2018.

AZEVEDO, P. F. de. Comercialização de produtos agroindustriais. In: BATALHA, Mário Otávio. Gestão agroindustrial: Gepai: Grupo de estudos e pesquisas agroindustriais. 3. ed. São Paulo: Atlas, 2012. p. 63112.

BARONE, L. A.; FERRANTE, V. L. S. B. Reforma agrária no Brasil do século XXI: bloqueios e ressignificações. In: DELGADO, G. C.; BERGAMASCO, S. M. P. P. Agricultura familiar brasileira: desafios e perspectivas de futuro. Brasília: MDA, 2017.

CHIODI R.; ALMEIDA G.; ASSIS L. O mercado convencional da banana: sujeição da agricultura familiar no Vale do Ribeira-SP. Desenvolvimento Em Questão, v. 18, n. 50, p. 146-165, 2020. DOI: https://doi. org/10.21527/2237-6453.2020.50.146-165

DE SOUSA FILHO, H. M.; BONFIM, R. M. Oportunidades e desafios para a inserção de pequenos produtores em mercados modernos. In: CAMPOS, Silvia Kanadani; NAVARRO, Zander (org.). A pequena produção rural e as tendências do desenvolvimento agrário brasileiro: ganhar tempo é possível? Brasília: CGEE, 2013. p. 71-100.

ELLIS, F. The Determinants of Rural Livelihood Diversification in Developing Countries. Journal of Agricultural Economics, v. 51, n. 2, p. 289-302, 2000. DOI: https://doi.org/10.1111/j.1477-9552.2000.tb01229.x ESCOBAL, J.; FAVARETO, A.; AGUIRRE, F.; PONCE, C. Linkage to Dynamic Markets and Rural Territorial Development in Latin America. World Development, v. 73, p. 44-55, 2015. DOI: https://doi.org/10.1016/j. worlddev.2014.09.017

GIL, A. C. Como elaborar projetos de pesquisa. 5. ed. São Paulo: Atlas, 2010.

GUANZIROLI, Carlos. Mercados viáveis para a inserção econômica dos agricultores familiares. In: CAMPOS, Silvia Kanadani; NAVARRO, Zander (org.). A pequena produção rural e as tendências do desenvolvimento agrário brasileiro: ganhar tempo é possível? Brasília: CGEE, 2013. p. 101-132.

HINRICHS, C. C. Embeddedness and local food systems: notes on two types of direct agricultural market. Journal of Rural Studies, v. 16, n. 3, p. 295-303, 2000. DOI: https://doi.org/10.1016/S0743-0167(99)00063-7 IBGE. Instituto Brasileiro de Geografia e Estatística. Sidra. Brasília, 2020a. Disponível em: https://sidra. ibge.gov.br/pesquisa/censo-agropecuario/censo-agropecuario-2017\#caracteristicas-produtores. Acesso em: 1으 abr. 2020.

IBGE. Instituto Brasileiro de Geografia e Estatística. Censo Agro 2017. Brasília, 2020b. Disponível em: https://censoagro2017.ibge.gov.br//. Acesso em: 6 mar. 2020.

INCRA. Instituto Nacional de Colonização e Reforma Agrária. Números da reforma agrária. Brasília, 2019. Disponível em: http://www.incra.gov.br/pt/n\%C3\%BAmeros-da-reforma-agr\%C3\%A1ria.html. Acesso em: 4 mar. 2020.

LOURENZANI, A. E. B. S.; LOURENZANI, W. L.; BATALHA, M. O. Barreiras e oportunidades na comercialização de plantas medicinais provenientes da agricultura familiar. Informações Econômicas, v. 34, n. 3, p. 15-25, 2004. Disponível em: http://www.iea.sp.gov.br/out/LerTexto.php?codTexto=1271. Acesso em: 24 jul. 2020.

MALUF, R. S. Mercados agroalimentares e a agricultura familiar no Brasil: agregação de valor, cadeias integradas e circuitos regionais. Ensaios FEE, v. 25, n. 1, p. 299-322, 2004. Disponível em: https://revistas.fee. tche.br/index.php/ensaios/article/view/2061. Acesso em: 13 maio 2018.

MAPA. Ministério da Agricultura, Pecuária e Abastecimento. Valor bruto da produção agropecuária (VBP). Brasília, 2020. Disponível em: http://www.agricultura.gov.br/assuntos/politica-agricola/valor-bruto-da-producao-agropecuaria-vbp. Acesso em: 6 mar. 2020.

MATTEI, L. O debate sobre a reforma agrária no contexto do Brasil rural atual. Política \& Sociedade, v. 15, edição especial, p. 234-260, 2016. DOI: https://doi.org/10.5007/2175-7984.2016v15nesp1p234 
NIEDERLE, P. A. Mercantilização, diversidade e estilos de agricultura. Raízes, v. 25, n. 1 e 2, p. 37-47, 2006. DOI: https://doi.org/10.37370/raizes.2006.v25.259

PLOEG, J. V. der. Mercados aninhados recém-criados: uma introdução teórica. In: MARQUES, F. C.; CONTERATO, M. A.; SCHNEIDER, S. Construção de mercados e agricultura familiar. Desafios para o desenvolvimento rural. Porto Alegre: Editora da UFRGS, 2016. p. 21-52.

SABOURIN, E.; TADEU DA SILVA, L. R.; DE AVILA, M. L. A rede de ação pública em torno da agroecologia e produção orgânica no Distrito Federal. Working Paper, Brasília, n. 2, 2019. Disponível em: https://agritrop.cirad.fr/594252/. Acesso em: 7 maio. 2020.

SABOURIN, E.; SÉGOLÈNE, T.; LÉA, E.; AVILA, M. L. Inovação social na comercialização de produtos orgânicos e agroecológicos da agricultura familiar no Distrito Federal. Sustentabilidade em Debate, v. 5, n. 3, p. 98-119, 2014. Disponível em: https://agritrop.cirad.fr/574802/. Acesso em: 7 maio 2020.

SABOURIN, E. Reforma agrária no Brasil: considerações sobre os debates atuais. Estudos, Sociedade $e$ Agricultura, v. 16, n. 2, p. 151-184, 2008. Disponível em: https://revistaesa.com/ojs/index.php/esa/article/view/301. Acesso em: 3 jun. 2020.

SCHNEIDER, Sergio. Mercados e agricultura familiar. In: MARQUES, F. C.; CONTERATO, M. A.; SCHNEIDER, S. Construção de Mercados e Agricultura Familiar: desafios para o desenvolvimento rural. Porto Alegre: Editora da UFRGS, 2016, p. 93-140.

SCHNEIDER, S.; CASSOL, A. Diversidade e heterogeneidade da agricultura familiar no Brasil e algumas implicações para políticas públicas. Cadernos de Ciência \& Tecnologia, v. 31, n. 2, p. 227-263, 2014. DOI: http://dx.doi.org/10.35977/0104-1096.cct2014.v31.20857

SCOONES, I. Sustainable Rural Livelihoods: A Framework for Analysis. IDS - Working Paper, Brighton, $\mathrm{n}$. 72, p. 1-22, 1998. Disponível em: https://opendocs.ids.ac.uk/opendocs/handle/20.500.12413/3390. Acesso em: 24 jul. 2019.

SEPULCRI, O.; TRENTO, E. J. O mercado e a comercialização de produtos agrícolas. Curitiba: Instituto Emater, 2010.

VON BRAUN, J.; KENNEDY, E. Agricultural commercialization, economic development, and nutrition. Baltimore: Johns Hopkins University Press, 1994. 